\title{
O TEU MESTRE- A DISTANCE LEARNING PLATFORM (RESULTS)
}

\author{
Daniel Azevedo \\ Polytechnic Institute of Viseu \\ Portugal \\ Paula Morais \\ Portucalense University \\ Portugal
}

\begin{abstract}
We live in a an age of change regarding mentalities and a consequent time of change in the learning processes. In this sense, it is necessary to create new methodologies and alternative practices to learn, teach and, more importantly, to learn how to learn. In recent years there has been a widespread commitment to use Information and Communication Technologies as a tool to support teaching. It is in this context that this work is inserted. The aim is to validate a digital educational resource of school that will be able to contribute to the aid of students of traditional education and also of those hospitalized and/or prevented from being present in the classroom. The proposed model was validated through a case study developed during the second and third periods of the 2014/2015 school year, involving special education students, in a hospital context, students of Mathematics A of the 12th grade of a Porto school and high school mathematics teachers.
\end{abstract}

\section{KEYWORDS}

Digital educational resources, educational platform

\section{INTRODUCTION}

The main objective of school is to prepare the student for life, in all its aspects. To achieve this difficult goal, school in parallel with the rest of society, has been adapted and has undergone through several technological changes. As early as 2002 Joly stated: "The technology that impacts today's society in a scary way has become a major school challenge" (p.1). With the recent technological upgrading of schools, this challenge has become easier to achieve, but there is still a long and controversial way to go, especially regarding to the use these new technologies.

Prensky (2007) is of the opinion that, although a major technological investment has been made in education in recent years, change has fallen short of expectations.

Gil (2014) points out that in the current situation, education has a favorable context since the nowaday students are digital natives, who have been born and live with digital devices and tools, demanding their use at school so it can be a space where they like to be and not out of step with the reality of their daily lives.

The main objective of this work is to validate a model of a DER ( Digital Educational Resources ) to enhance the learning of mathematics of students of traditional teaching and students hospitalized and/or prevented from being present in the classroom. In the specific case of mathematics, a recurrent problem of relatively low national test averages is observed in 2013 (8.2 points) and in 2014 (7.7 points).

If we consider the students hospitalized and / or prevented from being present in the classroom, these difficulties are even more evident. Correia (1997) considers these pupils with special educational needs to be special, as they exhibit certain specific conditions and may require support and special education services during all or part of their school career, in order to facilitate their academic, personal, social and emotional development. Most of these students are hospitalized for long periods of time and are faced with an unknown environment, with the aggravation of being away from their familiar, social and schoolar environment. 
Over the last few years, there has been a growing concern in supporting these students, especially those with cancer disease. In this sense, the XVII Portuguese Constitutional Government created Law No. 71/2009, which establishes a special regime for the protection of children and young people with cancer.

Although this legislation has been published, school support for these students is confronted with numerous difficulties

In this context, the OERs ( Digital Educational Resources ) can be seen as a means to battle the difficulties of teaching traditional students and, in particular, students who are hospitalized and / or prevented from attending classes, opposing isolation and linking them to the school community, providing new ways of learning.

\section{METHODOLOGY}

As mentioned previously, the main objective of this research is to propose a model of a DER to enhance the learning of mathematics to traditional students and to students hospitalized and/or prevented from being present in the classroom.

In this study qualitative and quantitative approaches will be used. We will also use a case study that was developed with a mixed approach, that allows evaluating the educational platform and collecting information to correct some aspects and improve it in the future. It should be noted, however, that like most case studies, it will not allow generalization on the model.

This case study was divided into 4 phases which can be summarized in:

1. The prototype of the platform "O Teu Mestre";

2. Presentation and formation of the platform;

3. Monitoring students' use of the platform;

4. Analysis of the results of the surveys completed by the interveners.

The participants in this study were:

A 12th grade class consisting of $\mathbf{1 7}$ public school students, many attending Mathematics A, from Fontes Pereira de Melo School in Porto; Four students signaled by the Acreditar Association (Association of Parents and Friends of Children with Cancer); These students are hospitalized and / or unable to be present in the classroom. Although there is legislation that provides for school support, in most cases this support does not materialize or is not adequate to their needs.Thus, due to a protocol established between the author and Acreditar, we considered in this study 4 students suffering from oncological disease and that alternated between hospital and outpatient regimens. Five mathematical teachers with more than five years of experience used the educational platform. Four of these teachers that used this platform are from the district of Viseu.

The teacher of the Fontes Pereira de Melo School used this platform as an educational resource in the classroom.

The collection of data was done through different methods and techniques that complement each other, namely: the logbook and a questionnaire survey. The logbook was one of the instruments of the case study, since it was necessary to record all the follow-up done to the students through the educational platform. This registration began at the beginning of the second school term of 2014/2015, when students signaled by Acreditar and Fontes Pereira de Melo were able to use the platform. Therefore, there was a monitoring of all the steps, which allowed to evaluate, redo and evaluate again, repeating this process countless times, in order to improve the service provided. In general, this register made possible to observe the students' difficulties at the pedagogical and technological levels. In this study we opted for 3 questionnaires, one directed to the students of the 12th grade group of the Fontes Pereira de Melo Schools Association, a second to the students signaled by Acreditar, and the last one to the teachers who had contact with the platform.

The objective of these questionnaires consisted in evaluating the prototype of the educational platform to which they had access. The design of the three questionnaires was based on the criteria of the Learning Object Review Instrument (LORI) table that analyzes the items: content quality, learning objective, adaptation and feedback, motivation, presentation and design, usability, accessibility, reuse, norm compliances. These items were addressed in the three questionnaires through questions distributed by 9 parts. The first 7 are closed questions, with simple indications about the purposes of each one, in order to try to obtain the desired information about the LORI criteria. The last two have open questions in order to gather opinions about the advantages or disadvantages of the platform and suggestions for it. 
The differences between the questionnaire given to the students of the Fontes Pereira de Melo School and the one given to the students signaled by Acreditar resides in the adequacy of the first question in the content item. The first questionnaire intends to analyze if the contents available meet the themes addressed in the refered School and, in the case of students signaled by Acreditar, if the contents made available meet their needs and difficulties. In the accessibility topic, a question was added: "Do you consider that the use of this platform is accessible in different electronic media (such as portable devices) and therefore an advantage in a hospital environment?". This question is intended to gather the opinion on whether accessibility in different electronic media is an advantage in the hospital environment.

In the questionnaire addressed to teachers, the questions were adjusted taking into account the professional aspect, ie, based on the criteria of LORI, what is the teachers' opinion regarding the evaluation of the platform, as a digital educational resource in use in classroom or as a complement to teaching.

We have also taken into account in the preparation of the questionnaires, ethical issues such as informed consent, anonymity and confidentiality of the data.

\section{DIGITAL EDUCATIONAL RESOURCES EVALUATION}

The increase in the quantity of pedagogical materials in computer support leads to the need to reflect on the technical and pedagogical quality of these materials, as well as their conditions of use; according to Lévy (2000) the diversity and multiplicity of available information is not a guarantee of any quality.

Ramos (2010) states that the evaluation of OERs is a concern in different countries and Portugal followed this concern and in 2004, the Portuguese Ministry of Education created a team of specialists and teachers with the objective of developing a collection system, dissemination, evaluation and certification of educational products in digital media (Costa, Peralta \& Viseu, 2007), which was designated by the SACAUSEF project (System for Evaluation, Certification and Support to the Use of Software for Education and Training). This project proposed the existence of three phases (Costa, Peralta \& Viseu, 2007): i) the submission of resources; ii) evaluation of resources in an educational context; iii) publication of the evaluation process in a portal, with the main objective of promoting the quality of the existing offer.

Belikov and Bodily (2016) consider a barrier to OER adoption is the amount of time that it takes to evaluate these new resources, some of which have not yet been through a review process. According to Hylen (2012) the idea is that it is not possible to guarantee the quality of such a high abundance of resources and materials that are made freely available on the web. In addition, the concept of quality is not peaceful, so in the next point we will approach the concept of quality in particular in a OER.

\subsection{The Quality Concept}

Quality can be defined as "an appropriate meeting between objectives of the interested parts and the needs as a result of a transparent participatory negotiation process in an organization" (Pawlowski, 2007, p 4).

According to Pinto (2007), the quality of information in a OER is determined by its ability to meet the expectations and needs of information and training of teachers and students who use them.

These definitions imply that quality assessment depends not only on the resource but on various context factors.

In order to guarantee the quality of a OER it is necessary to evaluate it. For Shaughnessy (2002) this evaluation process implies in itself the use of a set of tools and methods, such as the use of checklists designed by experts, use of surveys and observation, supervision and control of published information at the evaluation level. Some of these criteria will be discussed in the following section. In the particular case of the evaluation criteria of distance learning, there are numerous tables of evaluation criteria, we can refer to the table of LORI, Allen \& Mugisa and Pinheiro. These tables have the particularity of being able to evaluate a wider range of digital educational resources, from a simple presentation to the most complex structure of distance education. 


\subsection{LORI evaluation}

. In 2003, the Learning Object Review Instrument (LORI) was created by John Nesbit, Karen Belfer and Tracey Leacock, and has been one of the most widely used tools for evaluating OERs (Belfer, Nesbit, \& Leacock, 2002). In 2008 it is improved by the team consisting of Akpinar, Leacock and Nesbit (Akpinar, 2008).

The LORI is not only a simple tool, but also an infrastructure for evaluating digital educational resources that allows evaluators to evaluate and comment on OER (Leacock \& Nesbit, 2007). This evaluation is done using a five-point Likert scale [from low (1) to high (5)].

Fortunato, Marcelino e Souza (2018) considers that LORI's assessment is a simple tool to evaluate the variety and quantity of the existing OERs.

The LORI consists of nine items: Quality of content; Learning Objective; Adaptation and Feedback; Motivation; Presentation and Design; Usability and interaction; Accessibility; Reuse and Compliance Standards.

These points will then be considered in the light of the first wording of 2003 and also the changes made in 2008 .

- Content Quality - This refers to veracity, accuracy, balanced presentation of ideas, and the level of detail if it is appropriate for the target audience. Content should be free of errors.

- Learning Objective - Learning objectives are indicated. The resource presents an adjustment between learning objectives, activities, assessments, and student characteristics. Learning activities such as content and assessments should be tailored to previously defined objectives.

- Adaptation and Feedback - Content should be tailored to different students or to a student model. The resource should give feedback to different students or to student models.

- Motivation -The resource should have the capacity to motivate and arouse interest in a student population. It should be relevant to the personal goals and interests of the students for whom it is intended.

- Presentation and Design - You should present simple visual and auditory information for better learning and efficient mental processing. The resource should enable students to learn effectively. Feature presentations should minimize visual search, for example: text and graphics presentations should be clear, concise, and errorfree. In addition, the components of the screen do not interfere with the learning objectives in question.

- Usability and interaction - The feature is easy to navigate and there is predictability at the user interface. The UI design implicitly informs students about how to interact with the NET. Navigating through OER is simple. The behavior of the user interface is consistent and predictable.

- Accessibility - The design of OER buttons should have presentation formats that are accessible to students with special educational needs or who are mobile and do not have access to the traditional school. The resource shall be accessible through different electronic means including portable devices.

- Reuse - Can be used in various tasks, in various contexts and in students from different school paths. The resource should be independent of others and easily transferable to other learning and other contexts.

- Standards Compliance - Comply with relevant international standards and specifications. It should have a metadata identification that allows the user to easily identify the resource.

We considered that the LORI table presents the most balanced criteria, without being very specific or very comprehensive, unlike other tables analyzed, which focus on very particular aspects. In addition, the LORI table shows an evolution over the years and has been improved to meet current requirements.

\section{RESULTS ANALYSIS}

This particular chapter presents a detailed analysis of the results obtained from the responses to the evaluation surveys of the "O Teu Mestre" platform model. The questionnaires were sent by email to all participants.

A questionnaire was sent to the 17 students in the 12th grade, another to the 4 students signaled by Acreditar and a third to 5 high school teachers who teach mathematics, including Professor Maria José Losada. All respondents responded to the survey, which corresponds to a $100 \%$ rate of return.

As for the gender distribution, $47 \%$ of the students of the Fontes Pereira de Melo School are female and $53 \%$ are male. The students signaled by Acreditar are $3(75 \%)$ female and 1 male $(25 \%)$.

The average age of students is 18 years, according to the year of school attendance. 
As for teachers, 1 is male $(20 \%)$ and 4 are female $(80 \%)$, in relation to the average age of teachers is 43 , reflecting a reasonable professional experience.

The results presented are related to the LORI evaluation criteria.

\section{A) Content}

Regarding the content, the students of Fontes Pereira de Melo school, in relation to the first question "Do you think that the contents made available meet the topics addressed in the School?", 59\% of the students considered them useful and $41 \%$ very useful. Concerning question number 2 "Do you think that the information is presented in a language that you understand easily and in a logical way?", It is worth noting that $53 \%$ of the students assigned it level 4.

Regarding the students signaled by Acreditar, the following questions were presented: "Do you think that the contents made available meet your needs and difficulties?" and "Do you think that information is presented in a language that you understand easily and in a logical way?". All the students assigned them level 4 (very useful) thus expressing their degree of satisfaction with the contents of the platform.

In this criterion, teachers answered a first question "Do you consider the information made available on the platform accurate and appropriate to the subject?", $20 \%$ of the respondents considered it useful and $80 \%$ very useful. Regarding the 2 nd question "How do you rate the information presented regarding the level of detail and organization?" It was considered useful by $40 \%$ of the respondents and very useful by $60 \%$.

The third question was common to all (students and teachers) with the following text: "How satisfied are you with the following content - essential theoretical, quizzes, exams and intermediate tests and service have a doubt?"

It was verified that $82 \%$ of the students of Fontes Pereira de Melo school, regarding the last question of this group considered the item "theoretical essential" and $18 \%$ very useful, which demonstrates the relevance of a theoretical support in solving problems, as a synthesis / summary of the subject matter. $65 \%$ of the students attributed the rating of useful to the item quizzes and $35 \%$ of very useful. $71 \%$ of the students evaluated as useful access to the resolution of "exams and intermediate tests" and $29 \%$ very useful. $71 \%$ of the students surveyed were very satisfied with the "Tens uma dúvida" (Do you have a question?) item, which demonstrates the importance of clarifying doubts as they arise.

Graphically we can observe it in graph 1.

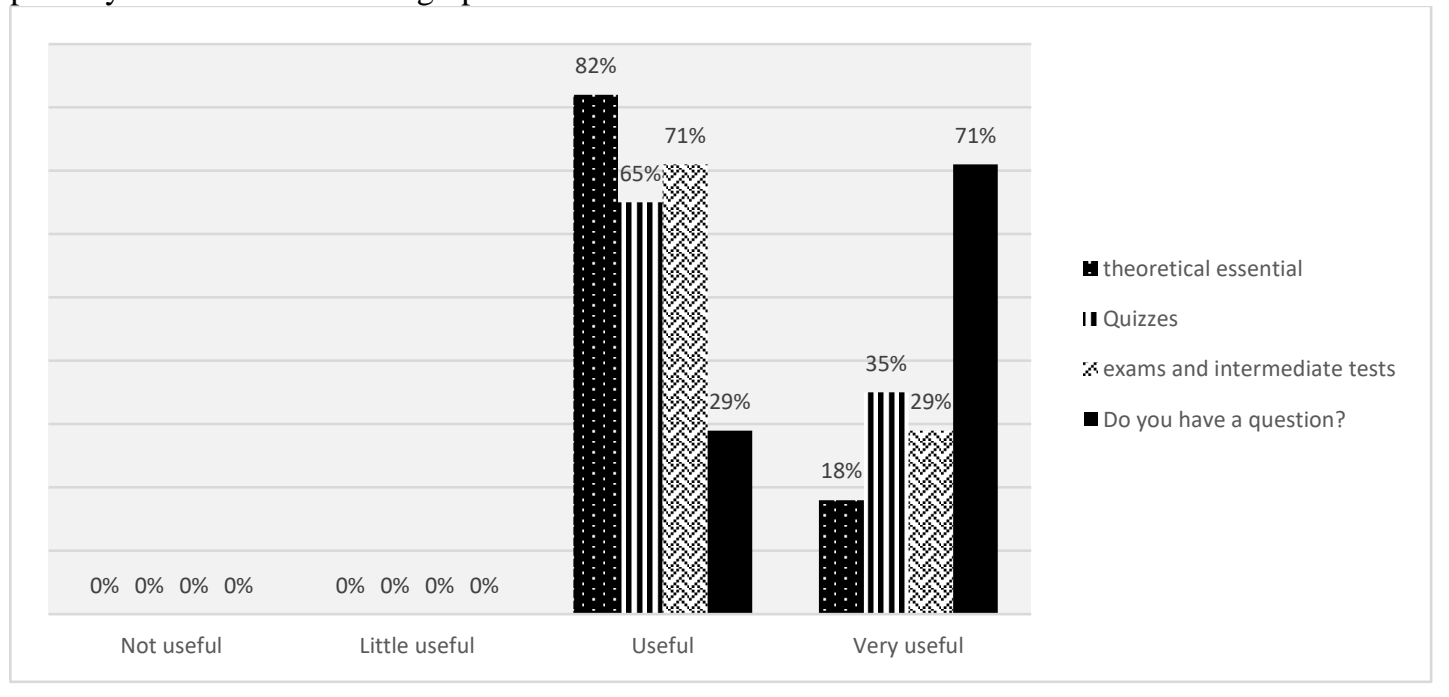

Figure 1: Level of satisfaction of FPM students in content

According the students indicated by "Acreditar" the items "theoretical essentials" and "intermediate exams and tests" were useful (75\%) and very useful (25\%)..

The quizzes item was considered useful by $50 \%$ of the students and very useful by the other $50 \%$.

All students were very satisfied with the service "Tens uma Dúvida?" since they, unable to attend classes regularly and contact directly with the teacher of the discipline, find in this service timely answers to their questions and difficulties. 
There were no students assigning levels 1 and 2 to the presented items, which shows the good acceptance of the contents available. We can see in graph 2 these results.

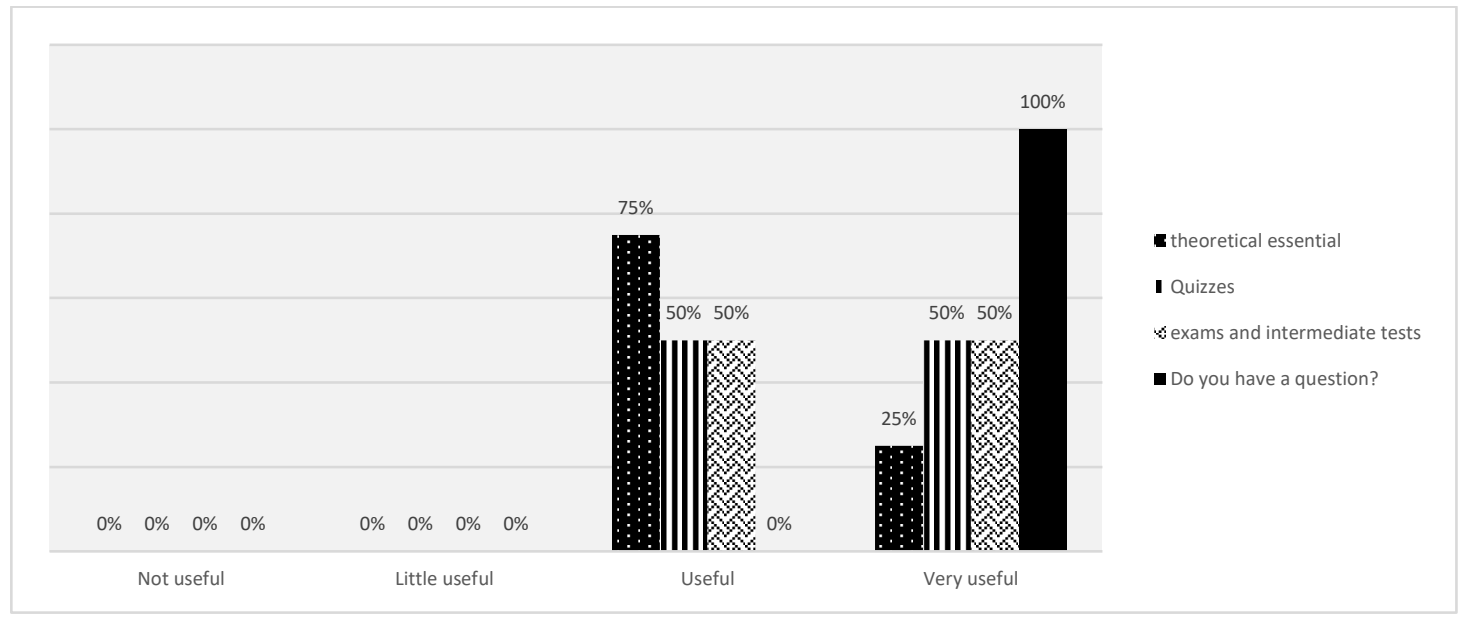

Figure 2: Acreditar students' level of satisfaction with content

With regard to teachers,

- $\quad 60 \%$ of the respondents considered the item "theoretical essential" useful and $40 \%$ very useful.

- $\quad 80 \%$ assigned level 4 to item quizzes and $20 \%$ considered it useful.

- $\quad 80 \%$ considered the item "intermediate exams and tests" useful, while $20 \%$ considered it very useful.

- $100 \%$ of teachers surveyed attributed the maximum score to the service item "Do you have a question?"

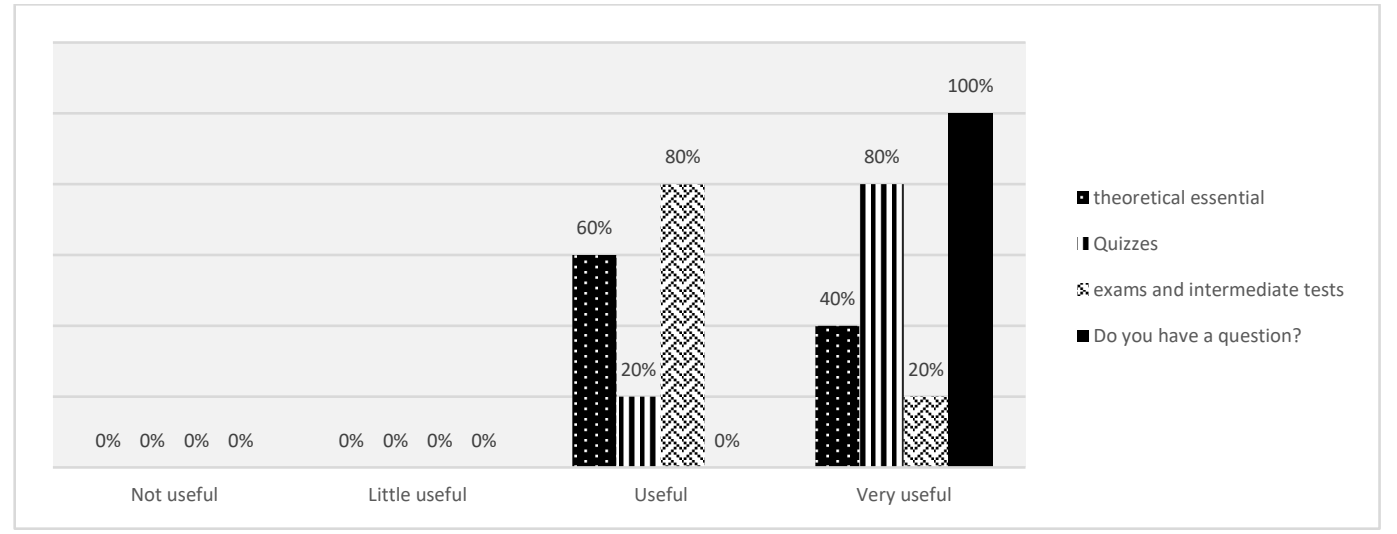

Figure 3: Level of teacher satisfaction with content

\section{B) Objectives}

In this item to the students of the Fontes Pereira de Melo school, two questions were posed: "Does the information provided on the platform meet your learning needs and doubts?"

It was found that $88 \%$ of the group of students considered the information useful and very useful, with only $12 \%$ who classified it as level 2 and therefore not very useful.

The questions addressed to the students identified by Acreditar, were "How do you classify the use of the platform with regard to the school attendance?" and "In case you are deprived of ongoing school support, do you believe that this platform can function as an important substitute for this even support? "

From the analysis of the results it is concluded that: 
- Regarding the ease of school monitoring, using the platform, $75 \%$ consider it useful and $25 \%$ very useful.

- $75 \%$ consider that the platform is a very useful support for students who are deprived of ongoing school support, acting as a substitute for this same support.

These figures confirm the need for these types of educational platform for students who, due to longterm illness, can not attend the classroom or benefit from more individualized teaching.

Regarding the issues addressed to teachers:

"Do you consider the platform made available as a means to facilitate the teaching of the discipline?" It should be noted that all the teachers who completed the survey considered the platform available as a facilitator of teaching the subject.

Also in this item, the question "Do you think it can work as an important complement in teaching the discipline?" was directed to all involved (students and teachers).

Regarding the students of Fontes Pereira de Melo school, it was evaluated positively by $94 \%$ of the them, being considered useful by $59 \%$ and very useful by $49 \%$. Only one student considered it to be of little value, which corresponds to $6 \%$ of respondents.

All the students signaled by Acreditar considered that the platform is a very useful complement in the teaching of the subject.

Regarding teachers, $60 \%$ considered the platform useful, constituting an important complement in the teaching-learning process of the student. $40 \%$ of the respondents attributed the maximum score, considering it very useful.

\section{C) Motivation}

The answer to the question "Do you think that the use of the platform motivates you to study the discipline?", shows that most of the students at Fontes Pereira de Melo are more motivated (level 3 and 4 answer) with use of the platform (71\%).

As for the students signaled by Acreditar, the answer to the question shows that $50 \%$ of the respondents considered this tool very useful as a motivating element for the study of the discipline.

The question for teachers has been rephrased with the text "Do you think using the platform motivates students to study the discipline?"

In this item it was verified that $80 \%$ of the teachers considered the platform very useful, functioning as a motivating agent in the teaching-learning process of the discipline.

\section{D) Graphic}

In this item, the students of Fontes Pereira de Melo were asked to answer the following question: "The text, graphics and images presented are: (1. not 2. yes 3. excellent) easy, clear, nice to see. "

The vast majority of respondents considered it excellent as to the ease and clarity in reading the text, graphics and images presented. 76\% of the respondents attributed excellent to the visual aspect of the platform.

Regarding the item graphics (text, graphics and images), they was considered excellent by all the respondents of Acreditar, which demonstrates that they appreciate the visual aspect, the clarity and ease of reading the information available.

All the teachers considered excellent the simplicity with which the platform presents the auditory and visual information. $80 \%$ of the respondents thought the information was presented in a clear way and $20 \%$ considered it to be excellent.

As for the graphic aspect, $80 \%$ of the teachers considered the platform very attractive.

\section{E) Usability interaction and accessibility}

In relation to this item the following questions were posed:

1- "How difficult is it to navigate the various fields of the platform?"

Regarding this first question, it was verified that all the students signaled by Acreditar considered easy to navigate on the platform, which shows the functionality and clarity of the associated tools.

Regarding the teachers, $40 \%$ considered it easy to navigate the various fields of the platform, while $60 \%$ considered this task very easy.

Relatively to the question "Do you think the platform is easy to interact with and that desktop icons are simple to use and intuitive?"

The majority of the students and teachers emphasized the ease of interaction with the platform, appreciating the intuitive and elucidative character of the iconography used.

The third question "Do you think information can be easily accessed and that it is simple to find the answers to your doubts?" 
We can conclude that, in a general way, the students were able to easily access the information provided. In fact, $65 \%$ of the respondents (students of Fontes Pereira de Melo school) considered access to the platform easy and $35 \%$ very easy.

As for of the students signaled by Acreditar, $75 \%$ consider that access to the platform is very easy and $25 \%$ easy.

Concerning the question addressed only to teachers "How does the platform consider the level of accessibility?", all teachers agreed that it was easy to access the platform.

The last question in this item was only directed to the students signaled by Acreditar: "Do you consider that the use of this platform is accessible in different electronic means (such as portable devices) and therefore an advantage in a hospital environment? (Yes / No response) "

With regard to this qestion, it is worth mentioning that all the students answered affirmatively to the possibility of using the platform in different electronic means, which represents a great advantage in a hospital environment.

\section{F) Reuse}

In this item students and teachers were asked to answer the following question: "How do you classify the platform with regard to: the possibility of storing the information, possibility of reuse and the possibility of printing content or sending by email."

$88 \%$ of respondents ( Fontes Pereira de Melo school) appreciated the possibility of storing the information, of reusing it as well as of printing it or sending it by email.

All the students signaled by Acreditar understood that it was easy to save the information, reuse it and be able to print it or send it by email.

$40 \%$ of teachers indicated being easy to keep information, while $60 \%$ understood it to be very easy.

Regarding the possibility of reusing, printing or sending by email, $80 \%$ of teachers understood it to be very easy.

\section{G) Interest}

In general, the students of Escola Fontes Pereira de Melo considered this platform of great interest, since $88 \%$ attributed to it the classification of very useful and $12 \%$ of useful.

Worthy of note are the same results regarding the platform's capacity for innovation.

All the students signaled by Acreditar considered this platform of great interest, attributing level 4 to it. The same results with respect to the platform's capacity for innovation.

All the teachers also pointed out the interest of the platform, being classified as very useful by $60 \%$ of them. It should be noted that all teachers have considered this platform to be very innovative.

\section{H) Advantages and disadvantages of the platform fpm}

Regarding this issue of opinion placed at the end of this group we can observe the following advantages:

For the students of Escola Fontes Pereira de Melo the platform presents a diversified set that meets the needs of the student; simplicity of navigation and ease of access to the platform; intuitive and user-friendly design; easy contact and flexible hours with a teacher through the "Tens uma dúvida?" service; possibility of assistance for students with reduced mobility or residing in places far from school.

The students signaled by Acreditar considered as advantages: the possibility and speed of access in different electronic media namely tablet and smartphone; flexibility of schedules for educational monitoring; easy navigation.

Teachers referred as advantages: allow review of content through interactive games; easy contact and flexible hours for a teacher through the "Tens uma Dúvida?" service; possibility of assistance for students with reduced mobility or residing in places far from school.

As disadvantages, the students of Escola Fontes Pereira de Melo highlighted: the lack of integration of the videoconference tool in the platform; 24-hour deadline to answer students' questions when requested by video; reduced number of queries in the "Tens uma Dúvida?" service.

The AC students pointed out the following: the impossibility of continuous monitoring; reduced number of queries in the "Tens uma dúvida?" service.

Regarding teachers, the disadvantages mentioned were: not having an area to put content; not allowing the creation of virtual groups and the management of the evaluation; lack of integration of the videoconferencing tool in the platform.

\section{I) Suggestions}

The main suggestions indicated were: extension of service to other disciplines; online classes and the possibility of networking among students. 


\section{CONCLUSION}

In this section the main conclusions of this research work are presented, whose main objective is to propose a model of a OER to promote the learning of mathematics for students of traditional teaching and for students hospitalized and / or prevented from being present in the classroom.

By analyzing the theoretical basis and results achieved, we can affirm that we reached the guiding objective of this research, that is, the creation of a model of a OER, the educational platform "O Teu Mestre", which enhances students' mathematics learning of traditional teaching and of students hospitalized and / or prevented from being present in the classroom.

In fact, we can conclude that this model of educational platform contributes to the success in the mathematics discipline, functioning as an important complement and motivating agent of the teaching-learning process, inside and outside the classroom, as evidenced by the answers to the questions of the quiz:

"Do you think that the platform can work as an important complement in the teaching of the discipline?" (All students in hospital context, 94\% of those attending regular school and $60 \%$ of teachers answered affirmatively);

"Do you consider that the use of this platform can act as a motivating agent for the teaching and learning of the discipline?" (71\% of regular students, $50 \%$ of those in a hospital setting and $80 \%$ of teachers said yes) .

In general, respondents were satisfied with the usability and interaction content, navigation, accessibility, graphic aspect and information.

We can conclude that the participants in this process realize that this platform, by allowing great flexibility in terms of space, time and learning pace, allows to rationalize resources, respect the needs and preferences of each one, facilitating the teaching- learning.

In the particular case of hospitalized students, it is notorious that the OER model presented here allows to support these students without the need of human resources with exclusive dedication to these students. It also allows content to be organized in counterpoint to the lack of autonomy of the school that involuntarily contributes to a disorganized teaching and not adequate to the needs and current reality of the student. In addition, the platform does not need a great training of the actors since it is intuitive, as we can verify in the results of the questionnaires.

As for the gigantism of information, this platform simplifies the contents by summarizing them, always based on the national curriculum.

The analysis of the obtained results allowed to conclude that this model of OER contributes to the success in the mathematics subject, functioning as an important complement and motivating agent of the teachinglearning process in the classroom and also outside it, as an instrument of fundamental support to pupils who, for reasons of health, are prevented from attending school regularly.

\section{Main study limitations}

The first limitation: the period of time in which this work was developed presents itself as a limitation to the scope of the study, to the technological aspects related to the creation of the platform and to the changes made during the study to improve it. On the other hand, the pedagogical aspect implied a rigorous work in what refers to the selection of programmatic contents of the discipline of mathematics of the 12th grade, the accomplishment of works of synthesis / summary of the matter, the placement in the platform of exercises and its resolution and the creation of videos.

The second limitation: the small number of students in the study questionnaire, especially in the hospital context, is related to logistic issues, namely the lack of a pedagogical team available to ensure a continuous and adequate response to all the requests of the students that use the platform.

\section{ACKNOWLEDGEMENT}

This research was supported by Acreditar Association and Fontes Pereira de Melo School from Oporto. 


\section{REFERENCES}

Akpinar, Y. (2008). Validation of a Learning Object Review Instrument: Relationship between Ratings of Learning Objects and Actual Learning Outcomes. Interdisciplinary Journal of E-Learning and Learning Objects, 4, 291-302.

Belfer, K., Nesbit, J., \& Leacock, T. $\quad$ (2002) LORI Manual. http://edutechwiki.unige.ch/en/Learning_Object_Review_Instrument

Belikov, O. \& Brigham, R. (2016). Incentives and barriers to OER adoption: A qualitative analysis offaculty perceptions. Open Praxis, 235-246.

Correia, L. M. (1997). Alunos com Necessidades Educativas Especiais na Classe Regular. Porto Editora.

Costa, F. A., \& Peralta, M. H. (2007). Primary Teachers' Competence and Confidence Level Regarding the Use of ICT. In Proceedings of World Conference on Educational Multimedia, Hypermedia and Telecommunications (pp. 46-52). Orlando: E Pearson \& P Bohman.

Gil, H. (2014). A passagem da Web 1.0 para a Web 2.0 e... Web 3.0 : potenciais consequências para uma «humanização» em contexto educativo. Tese de Doutoramento. Universidade do Minho.

Joly, M. (2002). A Tecnologia no Ensino: Implicações para Aprendizagem. São Paulo: Casa Do Psicólogo. Recuperado de http://www.scielo.br/pdf/pee/v6n2/v6n2a10.pdf

Leacock, T. L., \& Nesbit, J. C. (2007). A Framework for Evaluating the Quality of Multimedia Learning Resources. Educational Technology \& Society, 10(2), 44-59.

Pawlowski, J. M. (2007). The Quality Adaptation Model: Adaptation and Adoption of the Quality Standard ISO/IEC 19796-1 for Learning, Education, and Training. Educational Technology \& Society, 10(2), $3-16$.

Pinto, M. (2007). Evaluación de la cálida de recursos electrónicos educativos para el aprendizage significativo. Sacausef 2, 25-43. edu.pt/files/@crie/1225103966_03_CADERNOII_p25_43_MPpdf.pdf

Prenksy, M. (2007). How to teach with technology: Keeping both teachers and students comfortable in an era of exponential change. In Emerging Technologies for Learning (Vol. 2, pp. 39-47).

Ramos, J. L. (coord.), Teodoro, V. D., Fernandes, J. P. S., Ferreira, M. F., \& Chagas, I. (2010). Portal das Escolas: Recursos Educativos Digitais para Portugal. Estudo Estratégico. Lisboa: GEPE. http://www.gepe.min- edu.pt/np4/364.html

República, D. da. (2009). Lei no 71/2009. Lisboa, Portugal: Governo de Portugal.

Shaugnessy, M. (2002). Educational Software Evaluation. A contextual approach. Ph. d. dissertation Cincinnaty Unniversity.

Souza, M., Marcelino, R., Fortunato, I. (2018). LORI como método de avaliação de objetos de aprendizagem: estudo de revisão. Revista de estudos aplicados em Educação.

Torres, P. (2007). Laboratório On-line de aprendizagem: Uma experiência de aprendizagem colaborativa por meios de ambiente virtual de aprendizagem EUREK@KIDS. http://www.scielo.br/pdf/ccedes/v27n73/06.pdf 